\title{
Tsafon
}

Revue d'études juives du Nord

$74 \mid 2017$

La Déclaration Balfour, vers l'État d'Israël ?

\section{Anne Summers, Christian and Jewish Women in Britain, 1880-1940. Living with a difference}

Andreea Rota

\section{(2) OpenEdition}

\section{Journals}

Édition électronique

URL : https://journals.openedition.org/tsafon/440

DOI : $10.4000 /$ tsafon.440

ISSN : 2609-6420

Éditeur

Association Jean-Marie Delmaire

Édition imprimée

Date de publication : 1 décembre 2017

Pagination : 176-177

ISSN : 1149-6630

\section{Référence électronique}

Andreea Rota, « Anne Summers, Christian and Jewish Women in Britain, 1880-1940. Living with a

difference », Tsafon [En ligne], 74 | 2017, mis en ligne le 31 mai 2018, consulté le 24 juin 2021. URL :

http://journals.openedition.org/tsafon/440 ; DOI : https://doi.org/10.4000/tsafon.440

Ce document a été généré automatiquement le 24 juin 2021.

Tsafon. Revues d'études juives du Nord 


\title{
Anne Summers, Christian and Jewish Women in Britain, 1880-1940. Living with a difference
}

\author{
Andreea Rota
}

\section{RÉFÉRENCE}

Anne Summers, Christian and Jewish Women in Britain, 1880-1940. Living with a difference, New York, Palgrave Macmillan, 2017, 254 p., £ 69,99.

1 Entre 1880 et 1914, environ 150000 Juifs ont fui l'Europe de l'Est pour s'établir en Grande-Bretagne. Ces Juifs priaient en hébreu, lisaient et écrivaient dans un alphabet non-européen, étaient extrêmement pauvres et dépourvus de toute éducation profane. L'arrivée de cette vague d'immigrants a eu pour conséquence de transformer, non seulement la nature de l'anglo-judéité, mais aussi les relations entre les Britanniques, majoritairement chrétiens, et les Juifs dans leur ensemble. L'histoire est connue : craignant une montée de l'antisémitisme, les notables juifs cherchèrent à angliciser les nouveaux arrivants et à réduire l'impact que leur pauvreté pouvait avoir sur les fonds publics. Ils multiplièrent pour cela les œuvres philanthropiques.

Or, ces initiatives philanthropiques furent menées depuis le seul terrain où les femmes pouvaient jouir d'un statut d'égalité avec les hommes. Privées de droits politiques, empêchées de recevoir une éducation professionnelle, les femmes de la haute et moyenne société ont cherché à investir l'action sociale afin d'échapper à la division genrée entre sphère publique (domaine des hommes) et sphère privée (domaine des femmes). Mais les activités philanthropiques eurent d'autres vertus, sur lesquelles se concentre le présent ouvrage : elles permirent à des femmes, juives et chrétiennes, de se rencontrer sur un pied d'égalité, nonobstant les clivages confessionnels.

3 Anne Summers présente les activités des femmes juives dans le cadre de leur propre communauté religieuse, tout aussi bien que les interactions de ces femmes avec 
d'autres femmes appartenant à des Églises différentes. L'auteur analyse finement les réseaux de coopération qui se créent dans le cadre d'actions communes, comme par exemple la prévention et le secours apportés aux prostituées et aux filles immigrées au tournant du siècle dernier, ou encore le soutien aux réfugiés pendant les années 1930. Une part conséquente du volume est consacrée à la présentation des liens de coopération entre les différentes ligues religieuses en faveur du suffrage féminin. La Grande-Bretagne est alors le seul pays au monde à disposer d'une société suffragiste juive ; et c'est aussi le premier pays au monde à organiser une campagne interreligieuse en faveur du suffrage. L'ouvrage se concentre essentiellement sur les femmes des classes moyenne et supérieure; du moins sur celles qui ont rédigé des journaux intimes ou des lettres. Le titre de l'ouvrage, qui annonce une étude portant sur des femmes juives et chrétiennes, a cependant quelque chose de trompeur. De même en est-il de la couverture, où s'affichent côte à côte des suffragettes juives, catholiques, anglicanes et méthodistes. Le volume, loin de traiter à parité de ces différentes femmes, se concentre en premier lieu sur l'histoire des femmes juives; les informations concernant les différentes confessions chrétiennes ne sont utilisées que pour souligner les différences de statut et de reconnaissance dont bénéficient les femmes juives dans le cadre de leur communauté. Le volume aurait probablement gagné à annoncer plus clairement son sujet; d'autant que l'auteur propose un travail tout à fait novateur et passionnant sur les femmes juives et leur engagement social et politique entre les années 1880 et 1940. 